\title{
森林分布响应过去气候变化: 对未来预测的启示
}

刘鸿赝*, 印轶

北京大学城市与环境学院, 地表过程分析与模拟教育部重点实验室, 北京 100871

*联系人, E-mail: lhy@urban.pku.edu.cn

2013-03-15 收稿, 2013-07-03 接受, 2013-08-26 网络版发表

国家自然科学基金委员会创新研究群体科学基金(31021001)和国家自然科学基金(41071124)资助

摘要 植被动态可能导致全球碳循环和水循环的改变, 并反馈于气候变化. 本文以森林植被 动态为重点, 基于古生态学研究的成果论述了冰后期以来气候变化影响下植被动态的特点以 及植被响应气候变化的模式, 区分了气候对植被的胁迫作用、非气候因子对植被动态的缓冲 作用以及千扰事件对植被分布改变的驱动作用. 对过去研究的回顾表明, 由于植被系统的开 放性以及气候因子和非气候因子的共同作用，使得植被-气候关系远离平衡态，植被分布对气 候变化的响应不是线性的, 这也使得当前的植被分布与气候之间的关系难以量化. 过去类比

关键词

生物地理学 第四纪生态学

气候变化

孢粉

动态植被模型 法、空间代替时间和动态全球植被模型是目前预测未来植被动态的 3 种主要途径, 但都是建 立在植被-气候关系平衡态的基础之上. 提出动态全球植被模型较传统的经验性生物地理学 模型更全面地考虑了植被动态的主要过程、火的千扰以及不同植物功能类群对气候变化响应 方式的差异性, 是未来的发展方向, 但需要结合古生态学的相关成果, 将时空尺度、气候变化 本身的复杂性、非气候因子的作用、森林分布对气候变化的反馈以及人类活动对千扰的调控 作用纳入模型中.

森林和草原是陆地表面最占优势的两大类植被， 其中森林面积占陆地表面积的 $1 / 3$. 地球植被处于不 断的变化之中, 植被动态不仅强烈影响地球的碳平 衡 $^{[1,2]}$ 和水循环过程 ${ }^{[3]}$, 而且还反馈于气候变化 ${ }^{[4]}$. 未 来全球变暖的情景下森林会扩展还是会衰退? 人类 应对气候变化的措施, 如在边际生境的林草交错带 造林, 是成功扩大森林的分布还是会产生负面的效 果? 以上科学与实践方面的问题引起了科学界的广 泛关注 $^{[5]}$. 以中国为例, 为了应对气候变化, 中国计 划将森林覆盖的面积由目前的 20\%增加到 2020 年的 $23 \%$. 但在湿润区，由于物理空间的限制而缺少宜林 地, 当前的林草交错带是未来造林的优先区 ${ }^{[6]}$. 在未 来气候变化的前提下, 这一地区是否适合造林? 哪种 森林类型适合在这一地区生长? 回答这些问题需要对
未来气候变化背景下的植被动态做出准确的预测.

过去植被动态是预测未来植被动态的钥匙，而 当前的植被格局是预测未来植被动态的前提 ${ }^{[7]}$. 本文 在总结过去植被动态研究最新进展的基础上，分析 气候变化影响植被动态的规律, 总结植被响应气候 变化的模式, 探讨如何准确预测未来气候变化可能 导致的植被变化.

\section{1 不同时空尺度的植被动态及其研究手段}

植被动态研究属于生物地理学这一跨学科的研 究领域. 在过去 100 多年的发展历程中, 生物地理学 也从“研究生物有机体分布的学科”[8]发展成为“研究 各个尺度上生物有机体的分布、随时间的变化及其机 理”的学科 ${ }^{[9]}$. doi: 10.1007/s11434-013-6032-7 
在不同的时空尺度上, 植被动态的驱动因子不 同，植被系统内部的响应方式也不同. 在年内时间尺 度上，风、侵蚀、滑坡、洪水、地震、干旱等事件能 改变群落的组成和结构, 从而对群落内部过程(如生 产力)产生影响; 火和病虫害则主要在年-十年的尺度 上发生, 直接影响种间竞争和林窗动态; 百年尺度上 的人类活动能引发群落的次生演替过程; 而千年尺 度的气候变化/波动极可能引起物种的迁移; 冰期-间 冰期的气候旋回则是在万年的时间尺度上引发生态 系统的演化(图 1(a), (b)).

相应地, 在不同的时空尺度上, 对于植被动态研 究采用的研究手段也不同：研究短时间尺度(1 10 a ) 的植被动态过程主要依赖长期定位观测和控制实 验 ${ }^{[12,13]}$, 以及航空相片和卫星相片等各类遥感数 据 ${ }^{[14]}$; 研究中等时间尺度 $(100 \sim 1000$ a) 的植被动态过 程主要依赖树木年轮和历史文献等手段 ${ }^{[15]}$; 而研究 长时间尺度(1000 10000 a) 的植被动态过程, 则主要 依赖动植物残体和狍粉学证据 ${ }^{[16]}$ (图 1(c)).

不管是驱动因子还是植被的响应，其时间尺度 和空间尺度都涵盖一定的范围. 由于植被分布变化 属于大空间尺度的生物地理学过程, 本文侧重从大 的空间尺度进行总结.

\section{2 森林分布对过去气候变化的响应}

\section{1 植被响应过去气候变化的模式}

作为过去植被的代用指标, 狍粉证据在过去的 研究中常常被直接用来复原古气候. 然而, 如果在此 基础上得出植被响应气候变化的模式，则难免陷人
循环论证. 近年来, 越来越多的高分辨率的独立的气 候变化证据(如冰芯、石笋)不断出现, 全球及区域性 温度曲线不断得到修改 ${ }^{[17]}$. 这些独立证据的出现为 准确复原植被响应气候变化的模式提供了依据.

在传统的孢粉学基础上发展起来的第四纪生态 学(又称第四纪古生态学)主要研究植被响应过去气 候变化的生态机理 ${ }^{[10,16]}$. 近年来，在植被响应气候变 化的模式方面主要取得了以下新的进展.

(i ) 高纬度地区山地成为冰期植物避难所. 中 低纬度地区山地一般认为是植物在冰期的避难所. 过去的研究一直认为, 北半球高纬度地区的森林在 冰后期的变化是由低纬度地区的避难所逐渐扩散而 形成的. 由此推算的物种扩散的速率一般在每年几 十米到几百米 ${ }^{[18,19]}$. 近年来, 越来越多的研究认为这 一速率在自然状态下是难以实现的 ${ }^{[20]}$. 最近的研究 表明，即使在末次冰盛期，在北欧和北美北部地区 (如阿拉斯加)等地仍然存在森林的避难所 ${ }^{[20,21]}$, 说明 在局地地形条件下，森林能够在末次冰盛期 (LGM) 分布在高纬度地区 ${ }^{[22]}$. 中国北方的山地, 如太行山、 大兴安岭、长白山等, 在冰期的时候由于地形条件的 作用, 也很可能是树木的避难所 ${ }^{[23]}$.

古生态学与遗传学的结合为复原冰期植物的避 难所提供了依据 ${ }^{[21]}$. 由于花粉能够长距离传播, 不 能反映不同种群之间的演化关系. 而来自于母系遗 传的线粒体 DNA, 只能通过种子在短距离内扩散, 通过线粒体 DNA 可以反映过去某一时期植物的准确 分布，并区分现代不同种群之间的遗传关系，进而推 断物种推移的路径 ${ }^{[21]}$.

(ii) 中纬度地区的植被循环演化. 在欧洲和北
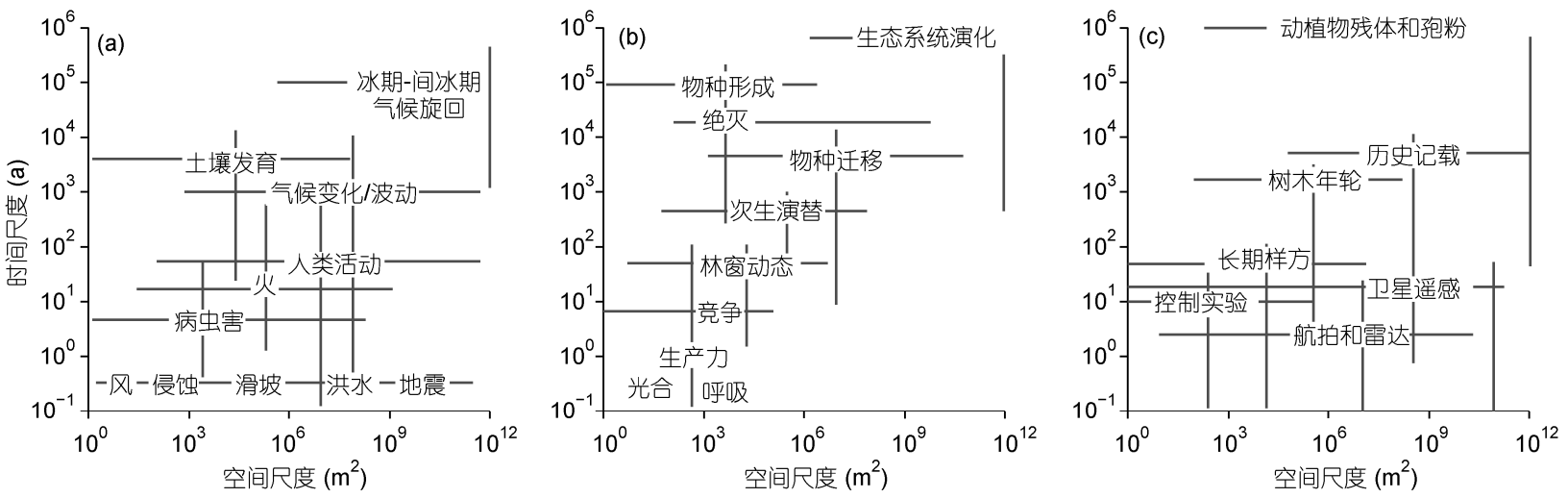

图 1 不同时空尺度植被动态的驱动因子(a)、响应方式(b)和研究途径(c) 修改自文献[10,11] 
美中纬度落叶阔叶林区, 最早提出了气候变化、土壤 演化和植被动态的循环演化模式, 具体内容为: (1) 从冰期到间冰期的峰值期温度首先升高, 尔后又 逐渐降低; (2) 冰川退缩后的新鲜土壤由于长期的营 养盐淋溶而由碱性变为酸性; (3) 植被由不耐荫的种 类变为耐荫的种类, 具体表现为桦属-栋属-松属-草 原分别占优势的 4 阶段模式. 虽然具体的动植物群落 存在差异，但是整个演化过程是类似的 ${ }^{[24,25]}$.

这一循环演化的模式在全球不同地区不同年龄 的沙丘土壤的植被演化中得到了验证. 研究结果表 明, 磷的淋失限制了森林在沙丘土壤上的发育 ${ }^{[26]}$. 与作为生物体组分而可再生的氮不同, 磷不能再生, 会从土壤中逐渐流失, 进而导致土壤中细菌和真菌 比例的变化, 养分的有效性下降 ${ }^{[26]}$. 养分有效性的 下降是阔叶林被针叶林取代, 进而被草原取代的主 要驱动因子 ${ }^{[25]}$.

然而，上述模式仅仅适合具有明显温度变化的 湿润气候区. 地处内陆地区的中国北方林草交错带全 新世以来的植被演替格局虽然也表现为桦属-栋属松属-草原分别占优势的 4 个阶段 ${ }^{[27]}$, 但演化的机制 并不完全相同. 季风强度控制的水热变化是影响中 国植被演化的关键因子 ${ }^{[28 ~ 30]}$.中全新世之后, 植被 对降水变化的敏感性增加, 对温度变化的敏感性降 低, 表明干旱胁迫逐渐加剧; 随干旱程度的加剧, 栋 属逐渐被更加耐旱的松属所取代, 并最终被草原植 被类群所取代 ${ }^{[27]}$. 这一时期植被演化与同样受干旱 驱动区域的植被变化特点较为相似, 如地中海 ${ }^{[31]}$ 和 非洲萨赫勒区域 ${ }^{[32]}$.

(iii) 不同植物类群的个性化响应. 基于孢粉学 研究, Davis ${ }^{[33]}$ 很早就提出了植物对过去气候变化的 个性化响应(individualistic response)模式. 同样, 由 于植物生态习性的不同, 生态种组或者植物功能类 群对气候变化也存在不同的响应模式 ${ }^{[22]}$. 树木和草 本植物是具有显著差别的两大植物功能类群, 同样, 它们对气候变化的响应也存在显著的差异. 草原植 被响应较快, 而森林成分时滞较长, 表现出比草原更 强的稳定性和滞后性，这可能是由于不同植被类型 以及不同物种的生态差异造成的. 森林植被对气候 变化的响应受树木生命周期的影响, 其迁移和扩展 速度不可能非常快; 而草原植被存在大量一、二年生 植物, 物种更新的频率相对较高, 周期相对较 短 ${ }^{[10,22,33]}$.
不同植物类群的个性化响应主要发生在气候明 显变化的转折期. 对北美晚第四纪植被历史的综述发 现不同的植物物种对千年尺度的气候变化存在个性化 的响应. 植被的分布与组成在末次冰盛期 (21000 17000 a BP)以及中晚全新世 $(7000 \sim 500$ a BP)变化不 明显, 但在晚冰期和早全新世(16000 8000 a BP)以 及近 500 年来变化最为明显. 种类分布的变化表现为 种群多度以及分布范围的个性化改变, 除了主要种 类北移以外, 还包括受干旱影响的东西迁移 ${ }^{[34]}$. 对 中国全新世植被演化的综述表明，植被组成和分布 的变化主要发生在早全新世气候由冷转暖的时期以 及 4500 a BP 前后气候由湿变干的时期 ${ }^{[30]}$.

植物生态种组或者功能类群的个性化响应可能 使得在某历史时期存在的植被类型现在已经不复存在 了. 这种群落称为“无现代相似体的群落”(no-analog 或 no modern analog). 这类无现代相似体的群落主要 出现在气候转折期, 可能的原因是气候变化速度太 快, 部分植物种类的扩散速度不及气候变化的速度, 由于不同的种类相对于气候变化有不同的时滞, 使 得群落发生重组 ${ }^{[35]}$. 如北美地区早全新世出现的 Fagus-Tsuga 和Picea-Alnus-Betula 现在依然存在, 而 晚冰期出现的一些森林类型(如 Picea-CyperaceaeFraxinus-Ostrya/Carpinus) 则不复存在了 ${ }^{[34]}$.

(iv) 气候变化的累积效应与植被的滞后响应. 植被对气候变化表现出较强的抵抗性, 对于短时期 的气候波动, 森林植被可能表现为生长减缓、郁闭度 下降、森林斑块收缩等, 并且由于避难所和种库的存 在, 原来的植被类型有较强的弹性和恢复能力, 并不 直接导致植被类型的变化; 只有在较长时期的气候 过程累积影响下, 森林类型才会最终改变 ${ }^{[36,37]}$.

由于植被响应气候变化的累积效应, 植被的响 应往往出现时滞(time lag). 时滞的长度在一些地区 可能达到数百年, 甚至千年. 先锋物种和顶极物种在 全新世初期进人群落的时间可以相差 4000 年甚至更 长, 全新世初期不稳定的气候导致先锋物种进人, 而 顶极物种只有等到气候条件稳定时才进入 ${ }^{[38]}$. 在非 洲萨赫勒地区, 虽然气候的干旱化在近 6000 年以来 是渐变的, 但森林被草原所取代是在过去 4300 年以 来才发生的 ${ }^{[32]}$. 然而, 低密度或小面积的森林片段 可能很难被狍粉证据检测出来，时滞也可能被夸 大 $^{[38]}$. 在气候的长期胁迫下, 森林的分布可能呈现 相对稳定的状况，而森林的大范围扩散和收缩可能 
与强的干扰(如火、病虫害)有关. 从某种意义上讲, 由于累积效应导致的植被滞后响应可能是由于气候 变化累积作用导致了干扰事件的增加 ${ }^{[40]}$.

植被对气候变化的时滞表明，植被与气候之间 并非完全处于平衡态, 植被对气候变化的响应可能 不是线性的, 而可能是气候变化累积到某一阈值之 后发生的改变. 如果考虑其他生物和非生物因子的 共同作用, 植被对气候变化的长期响应可能有一定 的惯性和不可逆性 ${ }^{[40]}$.

\section{2 环境因子在植被响应气候变化中的作用}

（i ）气候因子的胁迫作用. 气候变化对植被的 影响主要表现为长期胁迫. 在气候比较稳定的时期, 如末次冰盛期和中全新世, 植被虽然也受气候的胁 迫，但相对于气候转折期，植被比较稳定 ${ }^{[29]}$.

有观点认为当前全球的植被格局并不是由当前 的气候格局支配，而是由全新世以来的气候变化幅 度决定的 ${ }^{[41,42]}$, 说明了气候变化幅度对物种分布的 影响. 以中国北方林草交错带为例, 降水量较大的年 际波动提供了较不稳定的生境条件, 使得先锋群落 长期存在, 并且比顶极稳定群落具有更大的竞争优 势, 这也是作为先锋群落的桦林自全新世开始以来 一直在这一地区存在的原因 ${ }^{[43]}$. 这些对环境波动适 应能力较强、对气候和局地环境变化响应迅速的先锋 群落的长期存在, 也在一定程度上增加了区域植被 适应快速气候变化的能力. 当气候发生快速改变时, 速生先锋群落可以以较小的迁移距离快速扩张, 因 此区域植被总体格局表现为不同森林类型的消长变 化，而森林分布界限不一定出现明显的推移 ${ }^{[38]}$.

(ii) 气候以外因子的缓冲作用. 在全球或区域 尺度上, 气候变化是植被动态的决定性因子. 但在区 域尺度上, 影响植被的环境因子除气候以外, 还包括 土壤、地形、生物和人类活动等诸多因子, 是植被非 线性响应气候变化的原因.

植物生长主要依赖土壤提供水分和养分. 在全 球不同地区，土壤水分和养分通过不同方式影响植 被的动态，土壤的发育过程也受千年时间尺度上植 被动态的影响 ${ }^{[44]}$. 在土壤水分波动明显的地区, 如 北方冻土区、内陆干旱区和高山带, 植被的动态最容 易受到土壤水分的影响. 北方带广泛分布的冻土湿 地生态系统对小气候具有控制作用, 能避免气候变 暖时冻土的融化, 从而使得冻土的融化与气候变暖
之间的关系变得十分复杂 ${ }^{[45]}$. 受复杂的冻土融化时 空格局的影响, 北美大平原北部的林草交错带经历 了频繁的变化, 特别是局地林草比例的变化 ${ }^{[44]}$. 在 干旱区，植被的退化会加速土壤的侵蚀，而土壤中细 颗粒物质的流失又会改变土壤的渗透率和保水性能, 并降低土壤中养分的有效性 ${ }^{[46]}$. 在中国北方林草交 错带, 土壤的沙化与植被覆盖度的下降常常出现协 同变化 ${ }^{[47]}$. 高山带的土壤发育通常非常微弱, 土壤 的保水能力差. 虽然气候变暖有助于林线的上移, 但 土壤有效水分的不足可能导致植被响应气候变化出 现时滞. 如在瑞士东部, 挪威云杉的定居落后于适宜 气候条件的出现达 3000 年, 而在瑞士西部, 这一时 滞可以达到 6000 年 ${ }^{[48]}$.

复杂多样的地形条件对降水、辐射、风力活动、 水汽传输、土壤性状等进行重新分配和组合, 创造多 样化的局地小环境 ${ }^{[49]}$; 在区域尺度上各种生境类型 镶嵌存在的情况下, 即便气候发生快速变化, 某些生 境条件依然能够成为特定植被类型的避难所, 使其 度过极端气候时期, 并在气候复原时, 以较小的种子 传播距离, 快速复原, 因此地形条件创造的斑块镶嵌 植被格局对气候变化的抗性和稳定性较强.

生物之间的相互作用主要通过影响植物繁殖体 的传播、植物的定居以及种间竞争和群落演替进而对 植被动态产生影响. 动物是植物繁殖体传播的主要 载体, 也通过摄食对植物物种进行选择 ${ }^{[50]}$. 一些坚 果类木本植物如栎属 (Quercus) 和榛属 (Corylus) 主要 依赖动物传播. 过去一般认为极其偶然的事件可能 导致了坚果类木本植物由南向北迁移，如北美水青 冈(Fagus sylvatica) 的坚果由鸟类携带穿过五大湖 $区^{[10]}$. 气候变化是动物迁移的重要原因, 而动物迁 移带来了它们喜食的植物种子的传播, 然而这种观 点仍然存在争议. 有研究认为冰期时植物的繁殖体 在冰川覆盖的地区仍然保存下来了，在冰后期由于 气温升高导致冰川融化, 这些植物的繁殖体能够很 快萌发出新的个体. 而狍粉证据反映的冰后期植物 由南向北传播实际上更多的是由于冰川退缩后当地 植物的繁殖体逐渐萌发和定居的结果 ${ }^{[40]}$. 动物种群 在维持植被结构中也起着重要的作用，如栖息在森 林中的动物种群数量的减少可能影响了欧洲栋林向 水青冈林的转变 ${ }^{[51]}$.

总之, 在区域尺度上非气候因子的缓冲作用是 不可忽视的，森林在一些地区形成残遗植物群落就 
是一个很好的例子 ${ }^{[27]}$. 需要强调的是不同因子的作 用是不同的：地形因子通常是不变的，对植被动态的 影响是单向的; 而土壤与植被之间、动物与植物之间 相互影响、相互作用, 处于不断的变动之中.

(iii) 干扰事件. 相对于气候的长期胁迫, 干扰 事件是导致植被分布快速变化的直接原因. 影响森 林分布的干扰事件主要有火和病虫害等.

在气候条件恶化的情况下, 病虫害容易发生, 从 而导致森林植被的退化以致消失 ${ }^{[52]}$. 大量的实例说 明病虫害是森林大规模衰退的直接原因, 如 5000 年 前欧洲榆树的衰退 ${ }^{[53]}$. 另一方面, 真菌和昆虫对植 被动态也可能产生正面的影响. 物种繁殖体到达冰 川退缩后的裸地以后, 依靠先期到达的共生真菌吸 收贫痊土壤上的养分, 进而存活下来 ${ }^{[54]}$. 物种迁移 与共生真菌之间的关系也得到了现代生态学证据的 证实 ${ }^{[5]}$. 此外, 气候变化导致的物候变化对昆虫传 粉可能会产生重要的影响 ${ }^{[56]}$.

火是气候干旱化的产物, 但火的发生同时也取 决于植被能否提供足够的可燃物. 大量的实例表明 火是导致林草植被进退的直接原因. 气候-燃料-火的 循环模型决定了全新世北美大平原区北部的植被长 期维持在林草过渡的状态，林草更替的周期维持在 160 年左右, 在气候干燥时, 植被以草原为主，可燃 物充足, 火频率增加, 被火清除的草原有助于森林的 扩散 ${ }^{[57]}$.

总之, 由于气候、气候以外的环境因子以及干扰 事件的不同作用，森林分布不能完全随着气候的波 动而发生变化, 而表现为非线性模式: 当气候发生变 化时, 植被组成也不可能迅速到达和气候条件的平 衡状态. 受气候以外因素的影响, 植被响应气候变化 可能表现为与时空尺度相关的阶段式的变化. 虽然 极端事件可能导致植物生长减缓甚至死亡, 但是由 于区域性地形和土壤缓冲作用而残余的森林斑块的 存在、原来留存的种子萌发等各种生物因子的作用, 区域性的森林动态可能表现为更长时间尺度的斑块 动态, 而更大尺度上森林界限的推移则需要更大规 模和更频繁的干扰事件, 只有在长期气候趋势下才 能发生.

\section{3 当前气候变化是否正在改变森林的分布}

过渡性的植被类型或者不同植被类型的过渡地 带对气候变化最为敏感, 当前气候变化引起的森林
的扩张与收缩主要集中在生态过渡带.

尽管有大量的关于极地和高山地区的森林或灌 丛植被在向高纬度和高海拔地区扩展的报道 ${ }^{[58]}$, 但 对极地和高山地区的林线动态的研究一直不能回避 取样方法的影响. 基于林线附近全样地树木年轮分 布的研究表明, 100 多年以来, 西藏色季拉山高山林 线并没有往上爬升 ${ }^{[59]}$. 基于北美森林调查数据的分 析也发现，北美地区主要树种并没有随气候变暖而 出现北移 ${ }^{[13]}$. 相对于以往的选择性取样 ${ }^{[60]}$, 以上研 究基于全样地取样的年龄结构分析, 这样能更加准 确地认识森林分布的变化.

在北美等地的草原带出现了木本植物入侵 ${ }^{[61]}$. 但对全球森林死亡的综述则表明，在全球各地的林 草交错带普遍出现树木死亡和森林衰退 ${ }^{[62]}$. 木本植 物人侵草原主要与人类过度放牧有关. 而干旱林线 附近树木死亡主要是由于气候干旱化 ${ }^{[63]}$. 总体上, 当前的气候变化对森林的影响更多地表现为极端事 件(如极端干旱事件)对森林衰退的影响，而没有证据 表明气温升高引起的胁迫直接导致了森林分布的大 规模变化 ${ }^{[64,65]}$

\section{3 未来森林分布的动态预测}

\section{1 未来森林分布预测的主要途径}

传统的植被地理研究主要开展了潜在自然植被 (potential natural vegetation, PNV)的预测, 依据现在 的气候、土壤、地貌和植被特点以及植被的演替规律 来推断未来植被的发展 ${ }^{[66,67]}$. 近年来，随着对未来气 候变化认识的深人, 围绕不同的未来气候变化情景, 对未来植被动态的预测逐渐转向以气候变化为主要 驱动力的植被动态预测.

基于过去类比未来是预测未来森林分布的途径 之一. 随着工业革命以来全球变暖问题的提出以及 对未来全球变暖的预测逐渐被接受, 越来越多的研 究将中全新世和中世纪等高温时期的森林分布作为 预测未来气候变暖情景下森林分布的依据 ${ }^{[68]}$.

空间代替时间 (space-for-time-substitution) 是最 常使用的一种途径. 这种途径以对应于未来气候的 现状植被作为未来潜在的植被, 相当于在植被-气候 关系图中做位移, 把现在气候梯度上不同地点的植 被作为未来气候变化情景下的植被状况 ${ }^{[69]}$. 传统的 生物地理学模型实际上是空间代替时间途径的一种 
量化 ${ }^{[70,71]}$.

近年来, 机理模型的途径逐渐受到重视, 如动态 全球植被模型 (dynamic global vegetation models, DGVMs)整合了生物地理模型、生物地球化学模型以 及反映群落演替的林窗模型, 以植物功能类群表达 区域植被组成, 通过模拟气候限制引起的植物功能 类群比例的变化来反映植被动态. 目前的 DGVMs 中 开展植被分布变化预测以 LPJ(Lund-Potsdam-Jena)模 型为主 ${ }^{[72,73]}$.

在全球和大区域尺度上, 无论是对过去森林分 布的复原还是对未来森林分布的预测, 目前的工作 仍然很少. Prentice 等人 ${ }^{[74]}$ 最早基于生物群区模型 (BIOME)复原了全球和大区域尺度上过去森林的分布, 但限于数据, 这一复原仅限于末次冰盛期 (18 ka BP) 和中全新世大暖期 (6 ka BP; 图 2(a)). 这一途径的前 提是当前孢粉组合与植被类型的统计关系, 因此本 质上这一方法采用了基于现代类比过去的方法. 与 当前的森林分布相比, 中全新世大暖期的森林在北
半球高纬度地区、北美中西部地区以及北非等地的分 布比现在要广. Lucht 等人 ${ }^{[75]}$ 运用动态全球植被模型 LPJ 预测了未来森林分布的变化, 主要表现为在高纬 度地区向北扩展，在中低纬度地区则变化不明显(图 2(b))，对区域尺度上森林分布则有大量不同的预测 结果.

\section{2 基于过去类比未来的局限性}

虽然过去的气候变化与未来的气候变化在幅度 和过程上可能一致，然而，基于过去类比未来仍然存 在着不足. 首先, 温室气体浓度升高引起的气候变化 速率比冰后期以来任何一段时间内可能都要剧烈得 多 ${ }^{[78]}$. 此外, 现代的人类活动带来环境污染和景观 的碎裂化等新的干扰进一步增加了植被响应未来气 候变化的不确定性 ${ }^{[16]}$

简单地以相似的温度条件进行森林分布的类比 忽视了温度以外的因子在植被动态中的作用. 以北 美大平原内陆区植被对气候变化的响应为例, 由于
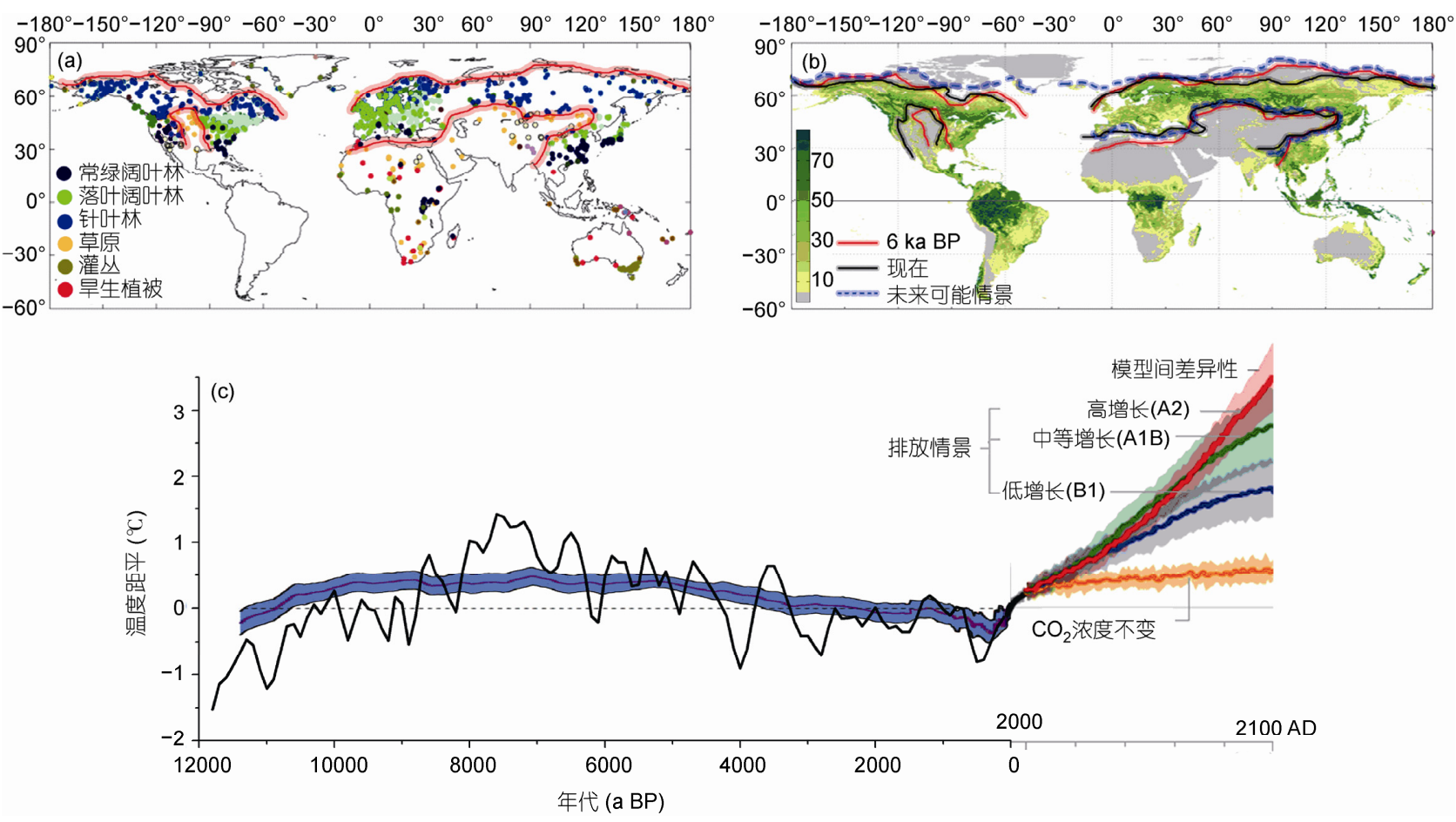

图 2 过去、现在与未来的温度变化及森林分布

（a) 基于沉积物狍粉组合重建的中全新世大暖期全球森林的分布 ${ }^{[74]}$. 红色线条表示森林分布的范围，南半球由于数据较少没有标出 (b) 过去、现在和未来北半球森林的分布. 过去植被界限与(a)中相同; 现代森林分布来自遥感数据 ${ }^{[76,77]}$, 不同颜色指示不同的森林覆盖 率; 未来森林分布范围来自 LPJ 模型的预测结果 ${ }^{[75]}$. (c) 全新世以来全球和中国区域温度距平(以 1961 1990 年为基准)及基于模型预测 的未来气候变化 ${ }^{[78]}$, 蓝色阴影区为全球平均状况 ${ }^{[17]}$, 黑色线条为复原的中国区域全新世温度变化 ${ }^{[79]}$.气候变化可以看出预测的 2100 年 的温度可能比全新世任何时期都要高 ${ }^{[17]}$ 
全新世夏季和冬季太阳辐射的季节差较现在更明显, 加上当时 Laurentide 冰盖的影响以及 Agassiz 湖变干 促使北美内陆地区干旱化, 当时的环境变化与现在 完全不同 ${ }^{[80]}$. 在全新世期间，局地尺度的因素强烈 影响了具体地点植被响应气候干旱化的起始时间和 速率, 只有 $1 / 3$ 的样点表现出对气候干旱化的即时响 应 $^{[81]}$. 因此可以认为, 由于环境因子的组合不同, 植 被响应未来的气候变化不一定可以从过去植被对气 候变化的响应中找到类似点.

古生态学证据表明, 干扰事件往往直接决定了 森林分布变化. 然而, 过去存在的干扰事件可能随气 候格局(如季节差异性)以及人类活动的变化而改变, 从而使得不能用过去的变化来类比未来的变化. 在 美国中北部的 Minnesota 地区，全新世中期 (8000 4000 a BP)经历了明显的气候干旱化, 但植被 对气候变化的响应与气候干旱化之间并不同步. 在 中全新世后期，尽管土壤湿度回升，草原植被依旧是 主要的景观类型, 原因是高的火频率限制了森林的 扩张 ${ }^{[82]}$. 植被对气候变化响应的非同步性说明, 由 于当前火频率的下降甚至火的缺失，用全新世中期 植被状况来说明植被对未来气候变暖的响应可能会 出现很大的偏差 ${ }^{[82]}$.

“非现代相似体群落”表明，未来的植被动态可 能不会是森林植被的进退, 而更多地会出现与现代 的森林植被完全不相同的植被类型. 也可能发生森 林覆盖的变化, 如森林的萨瓦纳(稀树草原)化 ${ }^{[83]}$.

\section{3 空间代替时间的局限性}

空间代替时间是基于当前植被-气候关系的简单 外推，其核心是用当前的水热条件描述植被分布的 现状, 然后给予未来水热条件预测植被的变化 ${ }^{[84]}$. 传统的生物地理经验模型通常建立在 4 个假设的基 础之上. 首先，植被和物种在现在和将来都与气候处 于平衡状态. 其次, 气候变化以后, 植被和气候的关 系不会发生改变. 第三, 被选择的气候变量对植被起 着至关重要的作用, 其他的次要相互关系没有考虑 进去. 第四, 物种的实现生态位不变. Box ${ }^{[70]}$ 最早开 发了全球尺度陆地植被分布定量模型, 它将全球植 被划分成 41 个生活型，选择了 8 个可预测的气候变 量(最热月均温、最冷月均温、年均温、年降水量、 年湿度指数、最高月平均降水量、最低月平均降水量 和最热月平均降水量), 在 65 个地点进行单点预测并
进行检验. 后人进一步改进了模型并通过大量的单 点预测来反映植被分布的变化, 如 Emanuel 等人 ${ }^{[71]}$ 根 据全球 8000 个台站的气候数据划分了 Holdridge 生命 带 ${ }^{[85]}$, 预测在未来气候变暖的情况下, 针叶林面积将 减少 37\%，冻原面积将减少 32\%，草地面积则将增 加 ${ }^{[11]}$

虽然基于水热条件描述植被分布并预测其变化 具有简洁性，但这一方法存在明显的局限性. 首先, 仅用少量的指标(温度、年降水量等)难以描述复杂的 区域植被格局形成过程，特别是气候极端事件和气 候波动与植被格局的关系仍然不是十分清楚 ${ }^{[86]}$. 其 次, 从植被演化的过程来看, 由于非气候因子的缓冲 作用，水热条件不能完全描述植被的分布格局，尤其 是在干旱限制区域 ${ }^{[87]}$. 对于大多数的植被类型来说, 它们利用的水分直接来自于土壤 ${ }^{[8]}$. 土壤水分含量 除了受制于降水外, 还受土壤质地和地形等因素的 影响 ${ }^{[89]}$. 同时, 不同的植物类群存在不同的水分利 用模式. 热带稀树草地(萨瓦纳)的树草共存格局是一 个非常典型的例子，一般认为树木主要吸收下层的 土壤水分, 而草本植物吸收上层的土壤水分, 即所谓 的土壤水分利用的“两层模型”[90,91]. 第三, 植物的生 长和繁殖以及植被的演替在一定程度上遵循生物学 和生态学规律而非仅受气候因子控制. 由于森林的 寿命长达数百年, 没有合适的指标用于表达这种复 杂的动态过程. 植被之间的演替关系也不能用水热 条件来表达, 如先锋种和顶极种占优势的群落可能 分布在同一地区, 并不能用气候因子来表示二者之 间的关系．在中国北方，白桦(Betula platyphylla)林 和栋 (Quercus spp.)林通常占据非常接近的气候生态 位 ${ }^{[92]}$. 同样, 对于过去植物群落的残遗, 植被-气候 关系的表达也可能出现异常值，如内蒙古草原带沙 地上残遗的油松林 ${ }^{[43]}$. 最后, 全新世以来物种的实 现生态位一直在变化之中，不变的是物种的基础生 态位 ${ }^{[84]}$

过去的研究中经常把不同植被类型的界限和气 候界限联系起来，试图用特定的气候國值来反映植 被分布的界限，如通常认为年降水量 $400 \mathrm{~mm}$ 是我国 湿润气候和干旱气候的界限, 也是森林和草原分布 的界限. 由于极地林线和高山林线都受温度限制, 一 些热量指标用来表示林线位置与气候条件的关系, 如最热月月均温 10,11 或 $12^{\circ} \mathrm{C}$ 的等温线、最热月日 平均最高气温 $15^{\circ} \mathrm{C}$ 的等温线、无霜期 $90 \mathrm{~d}$ 的界线 
等 ${ }^{[93]}$. 无论是对于林草交错带还是高山林线或极地 林线, 这些指标只能作为粗略描述林线位置的指示 体, 而不能作为林线格局的气候阈值. 主要原因在于 受地形、土壤和不同植物类群之间竞争的影响, 以及 植被对局地小气候的反馈作用, 林线通常表现为或 宽或窄的生态过渡带 ${ }^{[94]}$. 此外, 林线所在地区气象 台站稀少, 林线附近的气候指标均依赖于温度递减 率进行推算, 地形条件引起的复杂的小气候格局在 指标计算时无法得到体现 ${ }^{[95]}$.

\section{4 动态植被模型的问题与挑战}

20 世纪末发展起来的动态全球植被模型综合考 虑了植被动态的主要过程、火的干扰以及不同植物功 能类群对气候响应方式的差异性 ${ }^{[72,73]}$. 基于动态全 球植被模型 LPJ 的模拟结果表明, 在未来气候变化的 情景下, 森林不会大范围地消失或扩展分布, 而更多 地表现在生长的变化(如生物量的增加)以及树种的 替换(如落叶树种被常绿树种所取代)等方面 ${ }^{[75]}$. 虽然 动态全球植被模型的预测较经验性的生物地理学模 型更可靠, 但仍然存在以下的局限性.

首先, 动态全球植被模型仍然基于植被-气候平 衡态的前提 ${ }^{[72]}$. 而事实上植被一气候平衡态要求植被 变化的速率与气候变化的速率匹配 ${ }^{[96]}$. 对北方针叶 林的预测表明, 如果植被和气候处于平衡态, 针叶林 往北扩散的速率应该在每 10 年 17 50 km, 远远高于 全新世期间每 10 年 1 4.5 km 的平均速率 ${ }^{[97,96]}$. 过去 的预测没有考虑植被对气候变化响应的时滞或者设 定固定的时滞, 但对不同类群的植物而言其时滞是 不同的 ${ }^{[96]}$.

其次, 动态全球植被模型中将植物划分成对环 境条件(特别是气候条件)具有一致的适应方式的功 能类群, 在全球尺度上, 通常被划分为落叶针叶树、 常绿针叶树、落叶阔叶树、常绿阔叶树、 $\mathrm{C}_{3}$ 草本植 物、 $\mathrm{C}_{4}$ 草本植物等 ${ }^{[98]}$. 然而, 功能类群的划分主要考 虑植物的气候适应性, 没有考虑其演替关系, 如同样 属于落叶阔叶树的华属和落叶栎属植物, 前者出现 在演替的初期, 后者出现在演替的后期.

第三, 动态全球植被模型虽然属于机理模型, 但 在植被动态方面仅仅设置了几个气候阈值. 如 LPJ 模 型没有考虑地形条件, 对于土壤水分过程也进行了 简化, 仅仅将各地的土壤分为两层, 将全球划分为 9 种土壤类型, 每种土壤类型的上层和下层设置不同
的渗透速率和根系分布比例 ${ }^{[72]}$. 无论哪种预测途径, 都没有充分考虑植被的演替. 实际上, 现在快速人侵 新生境的物种或者类群未必能够长期存在, 顶极物 种进人新的生境往往需要更长的时间 ${ }^{[38]}$.

总之, 目前对于植被响应未来气候变化的预测 对植被系统的开放性以及植被-气候关系的复杂性考 虑得远远不够. 机理模型无疑是预测未来植被动态 的有效途径. 基于森林响应过去气候变化的研究成 果以及当前植被-气候关系的复杂性, 机理模型应该 朝以下方向发展, 也是未来研究的重点.

(i) 综合不同的时空尺度. 在不同的时空尺度 上, 植被动态的驱动力和响应模式不同 ${ }^{[10]}$. 目前全 球尺度的植被动态机理模型很少而区域或局地尺度 的模型很多. 将单一尺度的模型拓展到多尺度的模 型, 同时在模型中体现不同时空尺度上驱动力和响 应模式的差异性是未来的发展方向 ${ }^{[99]}$.

(ii) 考虑气候变化本身的复杂性. 在未来的预 测中, 气候变化的复杂性, 如气候的季节性变化, 还 远远没有考虑到, 植被响应的气候阈值过于简化, 需 要在未来的模型预测中加以完善 ${ }^{[80]}$.

(iii) 考虑非气候因子的作用. 地形、土壤和生 物因素等对气候变化的缓冲作用是植被响应气候变 化出现时滞的因素之一, 而这种缓冲作用仅仅体现 在局地尺度的模型中, 需要进一步在区域或全球尺 度的模型中得到体现 ${ }^{[100]}$.

（iv）考虑森林分布对气候变化的反馈. 植被分 布格局, 特别是森林分布的变化能够反馈气候变 化 ${ }^{[101]}$, 然而目前对这一反馈的机制及格局仍然处于 探索之中 ${ }^{[102]}$, 在将来的模型中需要得到体现.

( $\mathrm{V}$ ) 考虑人类活动对当前植被的改造. 在预测 未来植被动态的过程中, 必须认识到当前的植被大 都受到了人类活动的强烈影响. 人类活动不仅能够 改造植被的结构, 更重要的是调控了决定植被动态 的干扰，如人类过去有意或无意地用火或者防火已 经造成了当前植被组成和结构的变化. 这种强烈人 工干预下的植被对气候变化具有何种适应能力仍然 值得研究.

\section{4 结论}

对植被响应过去气候变化的回顾表明, 植被(尤 其是森林植被)是以一种非线性的方式响应气候变化. 由于植被系统的开放性, 生物因素和非生物因素的 
共同作用使得植被-气候关系远离平衡态. 而目前对 于未来植被分布预测的 3 种主要途径都建立在植被气候关系平衡态的基础之上. 动态全球植被模型较 传统的经验性生物地理学模型更好地考虑了植被动 态的主要过程、火的干扰以及不同植物功能类群对气
候响应方式的差异性，但需要结合古生态学以及当 前植被-气候关系的相关成果, 将时空尺度、气候变 化本身的复杂性、非气候因子的作用、森林分布对气 候变化的反馈以及人类活动对干扰的调控作用纳人 到模型中.

\section{参考文献}

1 Bonan G B. Forests and climate change: Forcings, feedbacks, and the climate benefits of forests. Science, 2008, 320: 1444-1449

2 Pan Y, Canadell J G, Ciais P, et al. A large and persistent carbon sink in the world's forests. Science, 2011, 333: 988-993

3 Gerten D, Schaphoff S, Haberlandt U, et al. Terrestrial vegetation and water balance-hydrological evaluation of a dynamic global vegetation model. J Hydrol, 2004, 286: 249-270

4 Claussen M. Late Quaternary vegetation-climate feedbacks. Clim Past, 2009, 5: 203-216

5 Harris J A, Hobbs R J, Higgs E, et al. Ecological restoration and global climate change. Restor Ecol, 2006, 14: 170-176

6 Zhang P, Shao G, Zhao G, et al. China's forest policy for the 21st century. Science, 2000, 288: 2135-2136

7 Petit R J, Hu F S, Dick C W. Forests of the past: A window to future changes. Science, 2008, 320: 1450-1452

8 Spellerberg I A, Sawyer J W D. An Introduction to Applied Biogeography. Cambridge: Cambridge University Press, 1999

9 Whittaker R J, Araújo M B, Jepson P, et al. Conservation biogeography: Assessment and prospect. Divers Distrib, 2005, 11: 3-23

10 Delcourt H R, Delcourt P A. Quaternary Ecology: A Palaeoecological Perspective. London: Chapman and Hall, 1991

11 Walker L R, del Moral R. Primary Succession and Ecosystem Rehabilitation. Cambridge: Cambridge University Press, 2003

12 Bertrand R, Lenoir J, Piedallu C, et al. Changes in plant community composition lag behind climate warming in lowland forests. Nature, 2011, 479: 517-520

13 Zhu K, Woodall C W, Clark J S. Failure to migrate: Lack of tree range expansion in response to climate change. Glob Change Biol, 2012, 18: $1042-1052$

14 Zhao X, Zhou D, Fang J. Satellite-based studies on large-scale vegetation changes in China. J Integr Plant Biol, 2012, 54: 713-728

15 Swetnam T W, Betancourt J L. Mesoscale disturbance and ecological response to decadal climatic variability in the American Southwest. In: Stoffel M, Bollschweiler M, Butler D, et al, eds. Tree Rings and Natural Hazards. Heidelberg: Springer Netherlands, 2010. 329-359

16 刘鸿雁. 第四纪生态学与全球变化. 北京: 科学出版社, 2002

17 Marcott S A, Shakun J D, Clark P U, et al. A reconstruction of regional and global temperature for the past 11300 years. Science, 2013, 339: 1198-1201

18 Birks H J B. Holocene isochrone maps and patterns of tree-spreading in the British Isles. J Biogeogr, 1989, 16: 503-540

19 King G A, Herstrom A A. Holocene tree migration rates objectively determined from fossil pollen data. In: Huntley B, Cramer W P, Morgan A V, et al, eds. Past and Future Rapid Environmental Change: The Terrestrial and Evolutionary Processes of Terrestrial Biota. New York: Springer Verlag, 1997. 91-101

20 Parducci L, Jørgensen T, Tollefsrud M. Glacial survival of boreal trees in Northern Scandinavia. Science, 2012, 335: $1083-1086$

21 Hu F S, Hampe A, Petit R J. Paleoecology meets genetics: Deciphering past vegetational dynamics. Front Ecol Environ, 2009, 7: 371-379

22 Stewart J R, Lister A M, Barnes I, et al. Refugia revisited: Individualistic responses of species in space and time. Proc R Soc B-Biol Sci, 2009, 277: 661-671

23 Qiu Y X, Fu C X, Comes H P. Plant molecular phylogeography in China and adjacent regions: Tracing the genetic imprints of Quaternary climate and environmental change in the world's most diverse temperate flora. Mol Phylogenet Evol, 2011, 59: 225-244

24 Iversen J. The bearing of glacial and interglacial epochs on the formation and extinction of plant taxa. Uppsala Univ Arsskr, 1958, 6: $210-215$

25 Birks H J B, Birks H H. The rise and fall of forests. Science, 2004, 305: 484-485

26 Wardle D A, Walker L R, Bardgett R D. Ecosystem properties and forest decline in contrasting long-term chronosequences. Science, 2004, 305: 509-513

27 Liu H, Xu L, Cui H. Holocene history of desertification along the woodland-steppe border in northern China. Quat Res, 2002, 57: $259-270$

28 Dykoski C A, Edwards R L, Cheng H, et al. A high-resolution, absolute-dated Holocene and deglacial Asian monsoon record from Dongge Cave, China. Earth Planet Sci Lett, 2005, 233: 71-86 
29 Zhao Y, Yu Z, Chen F, et al. Vegetation response to Holocene climate change in monsoon-influenced region of China. Earth Sci Rev, 2009, 97: 242-256

30 Zhao Y, Yu Z. Vegetation response to Holocene climate change in East Asian monsoon-margin region. Earth Sci Rev, 2012, 113: 1-10

31 Carrión J S, Munuera M, Dupré M, et al. Abrupt vegetation changes in the Segura mountains of southern Spain throughout the Holocene. J Ecol, 2001, 89: 783-797

32 Kropelin S, Verschuren D, Lézine A, et al. Climate-driven ecosystem succession in the Sahara: The past 6000 years. Science, 2008, 320: 765-768

33 Davis M B. Climatic instability, time lags, and community disequilibrium. In: Diamond J, Case T J, eds. Community Ecology. New York: Harper and Row, 1986. 269-284

34 Williams J W, Shuman B N, Web III T, et al. Late-Quaternary vegetation dynamics in North America: Scaling from taxa to biomes. Ecol Monogr, 2004, 74: 309-334

35 Williams J W, Shuman B N, Webb III T. Dissimilarity analyses of Late-Quaternary vegetation and climate in eastern North America. Ecology, 2001, 82: 3346-3362

36 Araújo M B, Pearson R G. Equilibrium of species' distributions with climate. Ecography, 2005, 28: 693-695

37 Moss R H, Edmonds J A, Hibbard K A, et al. The next generation of scenarios for climate change research and assessment. Nature, 2010, 463: $747-756$

38 Cole K L. Vegetation response to early Holocene warming as an analog for current and future Changes. Conserv Biol, 2009, 24: 29-37

39 Giesecke T, Hickler T, Kunkel T, et al. Towards an understanding of the Holocene distribution of Fagus sylvatica L. J Biogeogr, 2007, 34: $118-131$

40 Miller P, Giesecke T, Hickler T, et al. Exploring climatic and biotic controls on Holocene vegetation change in Fennoscandia. J Ecol, 2008, 96: 247-259

41 Araújo M B, Nogués-Bravo D, Diniz-Filho J A F, et al. Quaternary climate changes explain diversity among reptiles and amphibians. Ecography, 2008, 31: 8-15

42 Sandel B, Arge L, Dalsgaard B, et al. The influence of Late Quaternary climate-change velocity on species endemism. Science, 2011, 33: 660-664

43 Liu H, Cui H, Yu P, et al. The origin of remnant forest stands of Pinus tabulaeformis in southeastern Inner Mongolia, China. Plant Ecol, 2002, 158: 139-151

44 Ewing H A. The influence of substrate on vegetation history and ecosystem development. Ecology, 2002, 83: 2766-2781

45 Camill P, Clark J S. Long-term perspectives on lagged ecosystem responses to climate change: Permafrost in boreal peatlands and the grassland/woodland boundary. Ecosystems, 2000, 3: 534-544

$46 \mathrm{He} \mathrm{N}, \mathrm{Wu} \mathrm{L}$, Wang Y, et al. Changes in carbon and nitrogen in soil particle-size fractions along a grassland restoration chronosequence in northern China. Geoderma, 2009, 150: 302-308

47 Yin Y, Liu, H, He S, et al. Patterns of local and regional grain size distribution and their application to Holocene climate reconstruction in semi-arid Inner Mongolia, China. Paleogeogr Paleoclimatol Paleoecol, 2011, 307: 168-176

48 Gehrig-Fasel J, Guisan A, Zimmermann N E. Tree line shifts in the Swiss Alps: Climate change or land abandonment? J Veg Sci, 2009, 18: $571-582$

49 Sherrer D, Körner C. Topographically controlled thermal-habitat differentiation buffers alpine plant diversity against climate warming. J Biogeogr, 2011, 38: 406-416

50 Gill J L, Williams J W, Jackson S T, et al. Pleistocene megafaunal collapse, novel plant communities, and enhanced fire regimes in North America. Science, 2009, 326: 1100-1103

51 Lang G. Quatäre Vegetaionsgeschichte Europas. Jena: Gustav Fischer Verlag, 1994

52 Motz J E, Morgan A V. Holocene paleoclimate and paleoecology determined from fossil Coleoptera at Brampton, Ontario, Canada. Can J Earth Sci, 2001, 38: 1451-1462

53 Girling M A. The bark beetle Scolytus scolytus (Fabricius) and the possible role of elm disease in the early Neolithic. In: Jone M, ed. Archaeology and the Flora of the British Isles. Oxford: Oxford University Committee for Archaeology Monograph, 1988, 14: 34-38

54 Wilkinson D M. Mycorrizal fungi and Quaternary plant migrations? Glob Ecol Biogeogr Lett, 1998, 7: 137-140

55 Nunez M A, Horton T R, Simberloff D. Lack of belowground mutualisms hinders Pinaceae invasions. Ecology, 2009, 90: 2353-2359

56 Fabina N S, Abbott K C, Gilman R T. Sensitivity of plant-pollinator-herbivore communities to changes in phenology. Ecol Model, 2010, 221: 453-458

57 Brown K J, Clark J S, Grimm C, et al. Fire cycles in North American interior grasslands and their relation to prairie drought. Proc Natl Acad Sci USA, 2005, 102: 8865-8870

58 Walther G R, Post E, Convey P, et al. Ecosystem response to recent climate change. Nature, 2002, 416: 389-395 
59 Liang E, Wang Y, Eckstein D, et al. Little change in the fir tree-line position on the southeastern Tibetan Plateau after 200 years of warming. New Phytol, 2011, 190: 760-769

60 Wang T, Zhang Q, Ma K. Treeline dynamics in relation to climatic variability in the central Tianshan Mountains, northwestern China. Glob Ecol Biogeogr, 2006, 15: 406-415

61 Van Auken O W. Causes and consequences of woody plant encroachment into western North American grasslands. J Environ Manage, 2009, 90: 2931-2942

62 Allen C D, Hogg E H, Gonzalez P, et al. A global overview of drought and heat-induced tree mortality reveals emerging climate change risks for forests. Forest Ecol Manage, 2010, 259: 660-684

63 Williams A P, Allen C D, Macalady A K, et al. Temperature as a potent driver of regional forest-drought stress and tree mortality. Nat Clim Change, 2013, 3: 292-297

64 Ciais P, Reichstein M, Viovy N, et al. Europe-wide reduction in primary productivity caused by the heat and drought in 2003 . Nature, 2005, 437: 529-533

65 Liu G, Liu H, Yin Y. Global patterns of NDVI-indicated vegetation extremes and their sensitivity to climate extremes. Environ Res Lett, 2013, 8: 025009, doi: 10.1088/1748-9326/8/2/025009

66 Chiarucci A, Araújo M B, Decocq G, et al. The concept of potential natural vegetation: An epitaph? J Veg Sci, 2010, 21: 1172-1178

67 Loidi J, Fernández-González F, Palmer M. Potential natural vegetation: reburying or reboring? J Veg Sci, 2012, 23: 596-604

68 Fox D. Back to the no-analog future. Nature, 2007, 316: 823-824

69 Hendersen-Sellers A. Global terrestrial vegetation "prediction": The use and abuse of climate and application models. Prog Phys Geog, 1994, 18: 209-246

70 Box E O. Predicting physiognomic vegetation types with climate variables. Vegetatio, 1981, 45: 127-139

71 Emanuel W R, Shugart H H, Stevenson M P. Climatic change and the broad-scale distribution of terrestrial ecosystem complexes. Clim Change, 1985, 7: 29-43

72 Sitch S, Smith B, Prentice I C, et al. Evaluation of ecosystem dynamics, plant geography and terrestrial carbon cycling in the LPJ dynamic global vegetation model. Glob Change Biol, 2003, 9: 161-185

73 Prentice I C, Bondeau A, Cramer W, et al. Dynamic global vegetation modeling: Quantifying terrestrial ecosystem responses to large-scale environmental change. In: Canadell J G, Pataki D E, Pitelka L T, eds. Terrestrial Ecosystems in a Changing World. BerlinHeidelberg: Springer Berlin Heidelberg, 2007. 175-192

74 Prentice I C, Jolly D, BIOME 6000 Participants. Mid-Holocene and glacial-maximum vegetation geography of the northern continents and Africa. J Biogeogr, 2000, 27: 507-519

75 Lucht W, Schaphoff S, Erbrecht T, et al. Terrestrial vegetation redistribution and carbon balance under climate change. Carbon Balance Manage, 2006, 1: 6

76 DeFries R, Hansen M, Townshend J, et al. A new global 1-km dataset of percentage tree cover derived from remote sensing. Glob Change Biol, 2001, 6: 247-254

77 Hansen M, Townshend J, DeFries R, et al. Estimation of tree cover using MODIS data at global, continental and regional/local scales. Int J Remote Sens, 2005, 26: 4359-4380

78 Climate Change 2007: The Physical Science Basis. Contribution of Working Group I to the Fourth Assessment Report of the Intergovernmental Panel of Climate Change. Cambridge: Cambridge University Press, 2007

79 方修琦, 候光良. 中国全新世气温序列的集成重建. 地理科学, 2011, 31: 385-393

80 Williams J W, Shuman B N, Bartlein P J. Rapid responses of the prairie-forest ecotone to early Holocene aridity in mid-continental North America. Glob Planet Change, 2009, 66: 195-207

81 Williams J W, Shuman B N, Webb III T. Dissimilarity analyses of Late-Quaternary vegetation and climate in eastern North America. Ecology, 2001, 82: 3346-3362

82 Umbanhowar Jr C E, Camill P, Geiss C E, et al. Asymmetric vegetation responses to mid-Holocene aridity at the prairie-forest ecotone in south-central Minnesota. Quat Res, 2006, 66: 53-66

83 Freilich L E, Reich P B. Will environmental changes reinforce the impact of global warming on the rairie-forest border of central North America? Front Ecol Environ, 2009, 8: 371-378

84 Volez S D, Williams J W, Blois J L, et al. No-analog climates and shifting realized niches during the late quaternary: Implications for 21st century predictions by species distribution models. Glob Change Biol, 2012, 18: 1698-1713

85 Holdridge L R. Life Zone Ecology. San Jose: Tropical Science Center, 1967

86 Yin Y, Liu H, Hao Q, et al. Vegetation responses to mid-Holocene extreme drought events and subsequent long-term drought on the southeastern Inner Mongolia Plateau, China. Agric For Meteorol, 2013, 178-179: 3-9 
87 Liu H, Yin Y, Zhu J, et al. How did forest respond to Holocene climate drying at the forest-steppe ecotone in northern China? Quat Int, 2010, 227: 46-52

88 Seneviratne S I, Corti T, Davin E L, et al. Investigating soil moisture-climate interactions in a changing climate: A review. Earth Sci Rev, 2010, 99: 125-161

89 Liu H, Cui H, Pott R, et al. Vegetation of the woodland-steppe ecotone in southeastern Inner Mongolia, China. J Veget Sci, 2000, 11: $525-532$

90 Walter H. Ecology of Tropical and Subtropical Vegetation. Edinburgh: Oliver and Boyd, 1971

91 Scanlon T M, Albertson J D. Inferred controls on tree/grass composition in a savanna ecosystem: Combining 16-year normalized difference vegetation index data with a dynamic soil moisture model. Water Resour Res, 2003, 34: 1224

92 印轶. 中国半湿润半干旱区全新世森林演化及其驱动因子. 博士学位论文. 北京: 北京大学, 2012

93 崔海亭, 刘鸿雁, 戴君虎. 山地生态学与高山林线研究. 北京: 科学出版社, 2005

94 D'Odorico P, He Y, Collins S, et al. Vegetation-microclimate feedbacks in woodland-grassland ecotones. Glob Ecol Biogeogr, 2013, 22: 364-379

95 Holtmeier F K. Mountain Timberline: Ecology Patchinees and Dynamics. Dordrecht-Boston-London: Kluwer Academic Publishers, 2003

96 Kirilenko A P, Belotelov N V, Bogaturev B G. Global model of vegetation migration: Incorporation of climatic variability. Ecol Model, 2000, 132: 125-133

97 Davis M B. Quaternary history and the stability of forest communities. In: West D C, Schugart H H, Botkin D B, eds. Forest Succession: Concepts and Application. New York: Springer, 1981. 132-153

98 Haxeltine A, Prentice I C. BIOME3: An equilibrium terrestrial biosphere model based on ecophysiological constraints, resource availability, and competition among plant functional types. Glob Biogeochem Cycle, 1996, 10: 693-709

99 Pearson R G, Dawson T P. Predicting the impacts of climate change on the distribution of species: Are bioclimate envelope models useful? Glob Ecol Biogeogr, 2003, 12: 361-371

100 Fisher R, McDowell N, Purves D, et al. Assessing uncertainties in a second-generation dynamic vegetation model caused by ecological scale limitations. New Phytol, 2010, 187: 666-681

101 Dallmeyer A, Claussen M. The influence of land cover change in the Asian monsoon region on present-day and mid-Holocene climate. Biogeosciences, 2011, 8: 1499-1519

102 Lee X, Gu L, Katul G, et al. Observed increase in local cooling effect of deforestation at higher latitudes. Nature, 2011, 479: 384-387 